\title{
Identificación de dos locales de distribución de vino y aceite en relieves de Isola Sacra
}

(IPO A 169A=ISLIS 305; IPO A 169B=ISLIS 306)

Identification of two places for distribution of wine and oil in reliefs from the Isola Sacra

(IPO A 169A=ISLIS 305; IPO A, 169B=ISLIS 306)

PABLo OzCÁRIZ GIL

Universidad Rey Juan Carlos*

\begin{abstract}
RESUMEN
En 1930 Calza publicó dos relieves de terracota encontrados en Isola Sacra. En ellos se mostraban dos escenas relativas a la profesión del difunto que fueron identificadas como tabernae de venta de agua. Esta teoría se argumentaba en que en la inscripción de una de ellas está presente el término aquatari(us). En este artículo defendemos que se trata de dos

tabernae de venta de aceite y de vino como consecuencia de la identificación de la tipología de las ánforas. Por otro lado, destacamos que los tres tipos de ánforas olearias de uno de los relieves son totalmente coincidentes con los tres tipos de ánforas existentes en el Monte

Testaccio (Roma) en los niveles pertenecientes a finales del siglo I/ d.C.
\end{abstract}

ABSTRACT

* Área de Historia Antigua. Campus de Fuenlabrada. Camino del Molino s. n. ${ }^{\circ} 28943$ Fuenlabrada (Madrid), pablo.ozcariz@urjc.es. Este artículo ha sido realizado dentro del proyecto de investigación del grupo CEIPAC (Universidad de Barcelona) «Relaciones interprovinciales en el Imperio romano. Producción y comercio de alimentos hispanos (provinciae Baetica et Tarraconensis)" (HAR2008-00210) (2009-2011), financiado por la Secretaría de Estado de Universidades del Ministerio de Ciencia e Innovación. 


\section{PALABRAS CLAVE}

Ánforas olearias, ánforas vinarias, Dressel 20, Monte Testaccio, Ostia, Isola Sacra, tabernae, relieves de terracota, aguador.

\section{KEYWORDS}

Oil amphorae, wine amphorae, Dressel 20, Monte Testaccio, Ostia, Isola Sacra, tabernae, terracota reliefs, water seller.

El lugar conocido como Isola Sacra es un área comprendida entre Portus y Ostia que durante el mandato de Trajano fue transformado en una isla en el transcurso de las obras de la Fossa Traiana. Este lugar de paso se convirtió durante el Alto Imperio en una necrópolis de la que se han conservado un número importante de tumbas, así como una abundante cantidad de epigrafía y de elementos decorativos. Se trata de tumbas monumentales donde predominan los columbarios pertenecientes a distintos grupos familiares, aunque existe un amplísimo panorama tipológico'1.

Las inscripciones y los relieves recuperados muestran un fiel reflejo de la sociedad de Portus: médicos, artesanos, comerciantes, muchos de ellos libertos. No se trata de grandes personajes pertenecientes al ordo ecuestre y senatorial, quienes preferían ocupar un lugar en las cercanas vía Ostiense o la vía Laurentina. Sin embargo, esta "clase media» había podido enriquecerse lo suficiente como para poder permitirse un nivel de vida acomodado, como refleja su presencia en este complejo funerario².

\section{LOS RELIEVES DE TERRACOTA DE ISOLA SACRA}

En Isola Sacra, además de las inscripciones habituales referentes a los difuntos, se ha conservado un elevado número de relieves de terracota con escenas re-

${ }^{1}$ La bibliografía sobre Isola Sacra es abundantísima. Las excavaciones iniciales se llevaron a cabo por G. CALZA (La necropoli del porto di Roma nell'Isola Sacra. Roma, 1940; id., "La necropoli del 'Portus Romae», Notizie degli scavi di antichità, 7, (1931), pp. 510-542). Posteriormente fueron retomadas por I. BALDASARRE («La necropoli dell'Isola Sacra», Quaderni de la ricerca scientifica, 100-2, (1978), pp. 487-504; id., "Una necropoli imperiale romana: proposte di lettura», Journal of Classical Studies (AION), 6, (1984), pp. 141-149; id., "La necropoli dell'Isola Sacra (Porto)» en: HESBERG, H.; ZANKER, P., Römische Gräberstrassen. Selbstdarstellung. Status. Standard. München, 1987, pp. 125-138; id., «La necropole de l'Isola Sacra» en: DESCOEUDRES J.-P. (ed.), Ostie. Port et porte de la Rome antique. Geneva, 2001, pp. 385-390; id., «La necropoli dell'Isola Sacra» en: VAQUERIZO, D. (ed.), Espacio y usos funerarios en el Occidente romano 2. Cordoba, 2002, pp. 11-26). Más bibliografía en: ANGELUCCI, S. et alii, «Sepoltore e riti nella necropoli di Isola Sacra», Bollettino di Archeologia. Ministero per i Beni Culturali e Ambientali. 5/6, (1990), pp. 49-113; GERMONI, P., «La necropole de Portus a l'Isola Sacra: la fouille recente sur le cote oriental de la route antique» en: DESCOEUDRES J.-P. (ed.), Ostie. Port et porte de la Rome antique. Geneva, 2001, pp. 391-392; TAGLIETTI F., «Ancora su incinerazione e inumazione: la necropoli dell'Isola Sacra» en: HEINZELMANN, M., et al., Culto dei morti e costumi funerari romani. Wiesbaden, 2001, pp. 149-158; HELTTULA, A., et al., Le iscrizioni sepolcrali latine nell'Isola Sacra. Roma, 2007. Para una lista bibliográfica exhaustiva sobre Ostia, Portus e Isola Sacra, vid. http://ostia-antica.org/biblio.htm

2 D'AMBRA, E., «Imitations of life: Style, Theme and a Sculptural Collection in the Isola Sacra Necropolis, Ostia» en: D'AMBRA, E.; METRAUX, G.P.R., The Art of Citizens, Soldiers and Freedmen in the Roman World. Oxford, 2006, p. 74. 


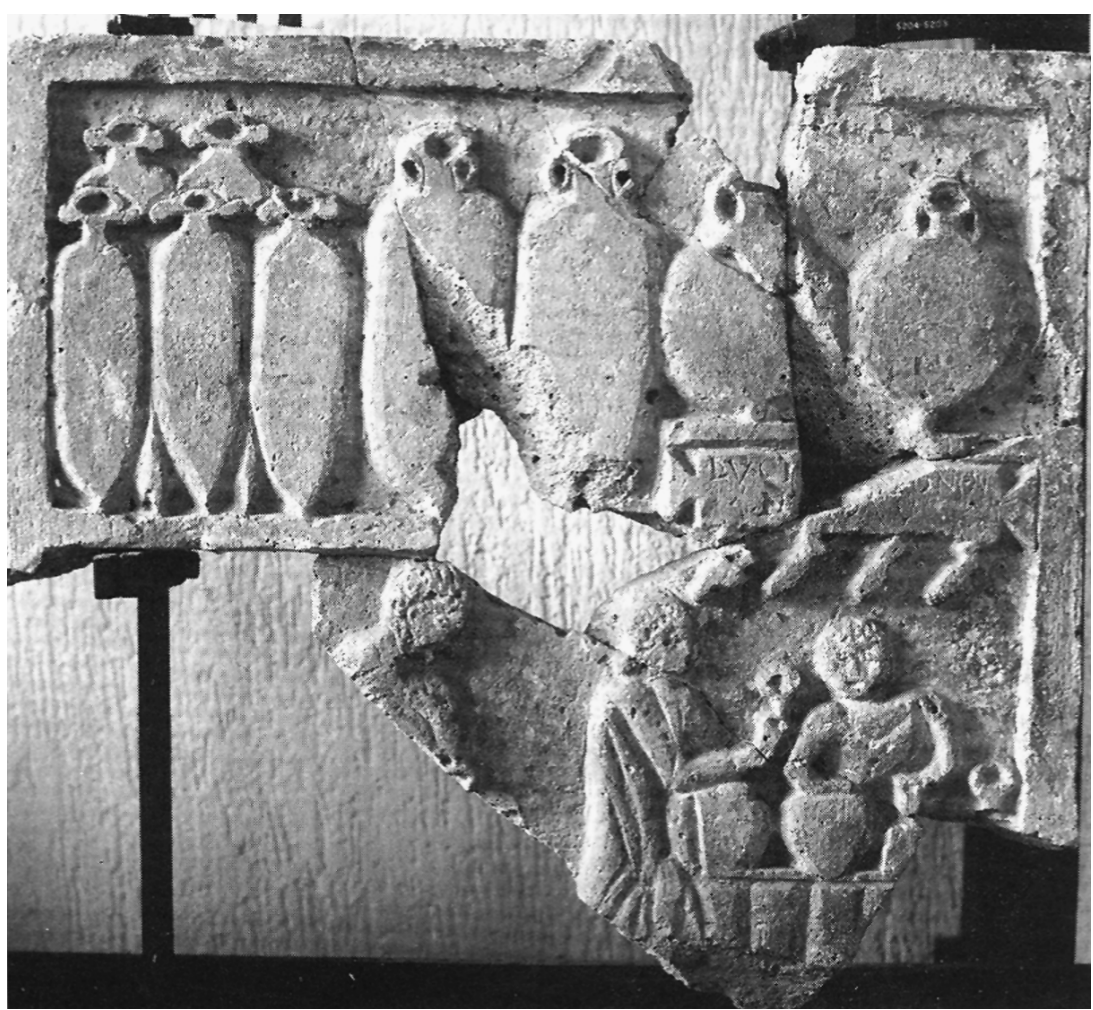

Fig. 1. Relieve IPO A 169B. Fuente: Pentti-Tuomisto, M., 306 (=IPO A 169b), en: Helttula A. et al., Le iscrizioni sepolcrali latine nell'Isola Sacra. Roma 2007 p. 311.

Thylander su lectura sería LUCI[FER] ONOVS / $N O^{8}$. Squarciapino propuso LUCI[FER] ONDVS / N... $O^{9}$. La lectura más reciente ha sido propuesta por PenttiTuomisto, como Luci[fer ? p]ondus $/ n[-1-2-]+d a s^{10}$. En la franja inferior se aprecia el espacio de atención al público. Puede identificarse a una persona detrás del mostrador atendiendo al público. A su alrededor se pueden distinguir varios elementos: sobre él aparecen colgando cuatro pequeños contenedores alargados, y su mano derecha se encuentra sobre uno de los dos contenedores medianos puestos sobre el mostrador. En su mano izquierda tiene algún objeto, probablemente el instrumento para llenar el contenedor del cliente. A su derecha parece identificarse un fragmento de otro contenedor. A la izquierda se encuentra el cliente, según Pentti-Tuomisto una mujer, con un objeto en la mano derecha. Más a la izquierda se encuentra fragmentado un posible segundo cliente o un esclavo.

8 THYLANDER, H., op. cit., A 169b (PI. XLIX: 2).

9 SQUARCIAPINO, M.F., op. cit., p. 193.

10 PENTTI-TUOMISTO, M., 306..., pp. 311-312. A pesar de que la opción pondus parece tener relación con la escena representada, no parece fácil integrarla en la inscripción. 


\section{EL RELIEVE IPO A 169A=ISLIS 305. ESTADO DE LA CUESTIÓN}

Se trata de un relieve con muchas semejanzas de fondo y de forma con el anterior: número de inventario 5858 con unas dimensiones de 49,2 por $51,2 \mathrm{~cm}$., con 0,9-3,5 cm. de fondo. También apareció fuera de contexto durante las mismas excavaciones, y fue conservado en el mismo lugar. Está realizado con el mismo material y la misma técnica. Ambos están divididos en dos planos y representan un mismo tipo de establecimiento. También cuenta con un piso superior en el que aparecen contenedores, aunque en este caso sólo se ha conservado un recipiente. En el piso inferior, a la izquierda hay un personaje atendiendo al público y en el centro un cliente. Encima del mostrador se conservan dos pequeñas jarritas alargadas colgando del techo. En el propio mostrador se encuentra la inscripción Lucifer / Aquatari. Thylander creyó (al igual que la gran mayoría de autores) que en la segunda línea se encontraba la referencia a su profesión: vendedor de agua. Solin, sin embargo, cree que se trata de un cognomen, bien de su patrono, o bien el de su padre, aunque cree esta opción menos verosímil ${ }^{12}$. Pentti-Tuomisto, recogiendo

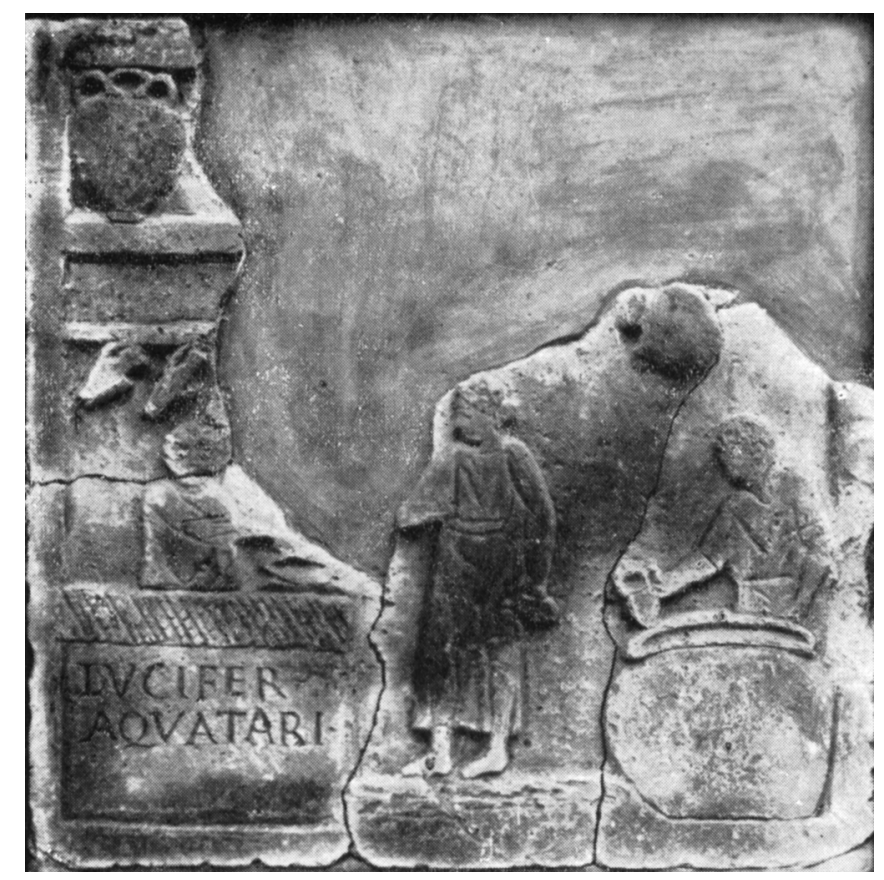

Fig. 4. Relieve IPO A 169A. Fuente: Squarciapino, M.F.,

Piccolo corpus dei mattoni scolpiti ostiensi. Bulletino della Commissione

Archeologica Comunale di Roma 76, 1956-1958 tab. V.

12 SOLIN H., «Analecta Epigraphica. CXIII: Zu Ostiensischen Inschriften». Arctos, Acta Philologica Fennica, 21, (1987), p. 123. L’Anée Épigraphique (1987, 177i) interpreta mal el texto de Solin al reproducir sólo la opción de que fuese el patrono de Lucifer. 
el resto de opiniones, opta por realizar una lectura de Lucifer Aquatari sin ningún desarrollo posterior ${ }^{13}$. Mientras que en el relieve anterior los clientes acudían hacia la derecha de la imagen, en este caso lo hacen hacia la izquierda. Esta diferencia hace que ambas escenas estén concebidas en torno a un mismo punto de referencia simétrico, ya que en varias tumbas se han conservado escenas de este tipo por parejas, separadas de una inscripción central' ${ }^{14}$. En IPO A 169A también se ha conservado la zona más alejada del mostrador. En ella se puede observar a otro personaje (quizás un esclavo) que se encuentra apoyado con una jarra sobre otro recipiente de gran tamaño, de boca ancha. Pentti-Tuomisto cree que puede tratarse de un dolium. Calza señaló que este gran recipiente podría ser de piel, por la sinuosidad del borde ${ }^{15}$. Sin embargo, creemos que el ancho borde del recipiente delata que se trata claramente de un dolium.

\section{COINCIDENCIAS PREVIAS ENTRE AMBOS RELIEVES}

El elemento que ha unido definitivamente ambos relieves, además del diseño, ha sido la coincidencia en el nombre propio de la inscripción. La semejanza de forma, fondo y de los nombres representados en ambas inscripciones (Lucifer y Luci[fer?) ha influido en la identificación de ambas como pertenecientes al mismo personaje. Puesto que en el primer caso se entendió que Aquatari hacía referencia a su labor profesional, se entendió por extensión que en el caso de IPO A 169B se trataba de lo mismo, un vendedor de agua o al menos de bebidas, ya que en este caso la inscripción no hacía referencia al producto de venta. Sin embargo, parece más razonable la opinión de Solin señalada anteriormente, según la cual Aquatari sería un cognomen que, a la vista de su taberna, quizás pudiese coincidir con la labor profesional de Lucifer.

\section{IDENTIFICACIÓN DE LAS ÁNFORAS}

Para intentar profundizar en las funciones de los dos establecimientos son de vital importancia el tipo de ánforas representadas en ambos relieves, ya que son perfectamente identificables ${ }^{16}$. En IPO A 169B, las dos ánforas situadas a la derecha con forma globular son, sin ningún género de dudas, del tipo Dressel $20^{17}$. Esta tipología tiene su origen en las orillas del Guadalquivir y contenía exclusivamente

13 PENTTI-TUOMISTO, M., «305 (=IPO A 169a)», en: HELTTULA A. et al., Le iscrizioni sepolcrali latine nell'Isola Sacra. Roma, 2007, p. 311.

${ }^{14}$ Ad ex., tumbas n. ${ }^{\circ}$ 29, 30, 78 o 100 (CALZA, G., La Necropoli del Porto...).

15 CALZA, G., La necropoli del 'Portus Romae..., p. 540.

16 PEÑA (The urban economy during the early dominate: pottery evidence from the Palatine Hill. Oxford, 1999, p. 23) ya identificó las ánforas del relieve IPO A 169B, aunque se limitó a señalar que se trataban de Dressel 20, Keay 3 (Africana 1 Piccolo) y Keay 9/11 (Tripolitania 2/3) sin entrar en más detalles ni hacer ninguna otra interpretación de los relieves. Sin embargo, no identificó el ánfora del relieve IPO A 169B.

17 Puede encontrarse una abundante bibliografía de las Dressel 20 en: BERNI MILLET, P., Epigrafía anfórica de la Bética. Nuevas formas de análisis. Barcelona, 2008; id., Las ánforas de aceite de la Béti- 
aceite de oliva. Era exportada a todo el territorio romano, destacando Roma, Galia, Germania y Britannia. Pero llegaba incluso más allá, a lugares como Alejandría, o tan lejanos como la India. Estos contenedores pesaban entre 28 y $29 \mathrm{~kg}$., a los que habría que añadir 70,63 kg. de las 216 libras de aceite (78,75 litros) que solían contener como capacidad estándar. Por las formas de las Dressel 20 del relieve, especialmente por el cuello corto y las asas semicirculares, podrían datarse a partir del tercer cuarto del siglo II d.C. ${ }^{18}$, lo que encajaría con el contexto cronológico de estos relieves de terracota. Es decir, que se trata de un tipo anfórico suficientemente conocido y estudiado, que no admite dudas sobre su identificación con las ánforas del relieve IPO A 169B.
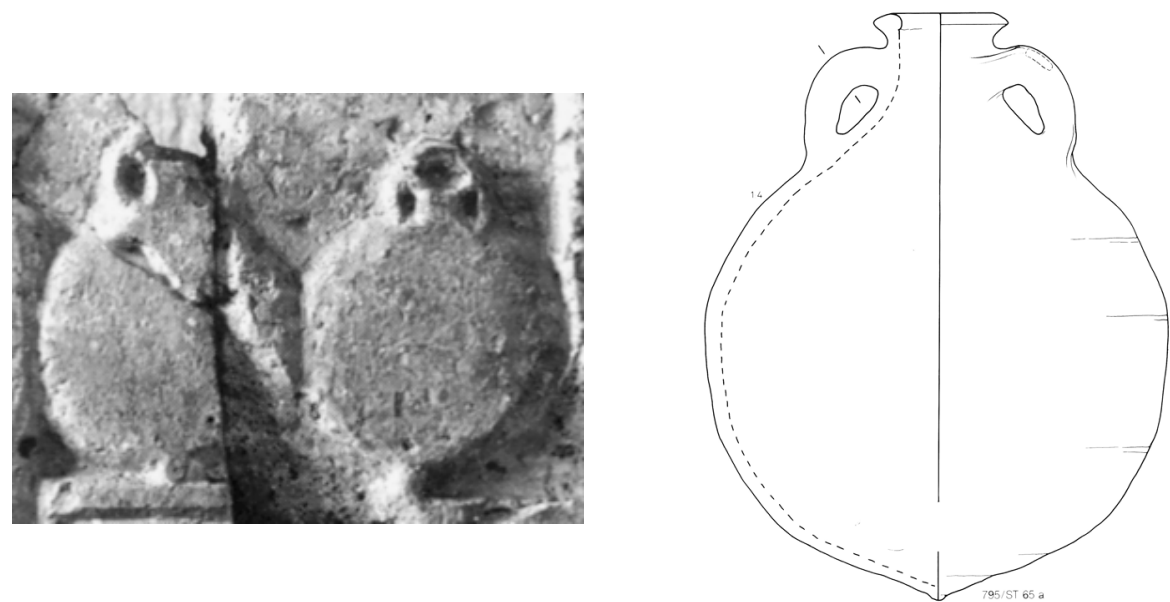

Figs. 5 y 6. A la izquierda, detalle de las ánforas Dressel 20 del relieve IPO A 169B. A la derecha, dibujo de un ánfora Dressel 20 de finales del siglo II d.C. Fuente fig. 6: Martin-Kilcher, S., Die römischen Amphoren aus Augst und Kaiseraugst. Augst, 1987, tab.45).

ca y su presencia en la Cataluña Romana. Barcelona, 1998. Sobre la difusión de las ánforas Dressel 20 cf. REMESAL, J., La annona militaris y la exportación de aceite bético a Germania. Madrid, 1986. Sobre la epigrafía de las Dressel 20, cf.: AGUILERA, A., "Los tituli picti delta del convento astigitano en el primer tercio del s. III d.C.» en: Congreso Internacional Ex Baetica Amphorae. Conservas, aceite y vino de la Bética en el Imperio Romano (Écija y Sevilla, 17 al 20 de Diciembre de 1998). Écija, 2001, pp. 12311240; id., «Evolución de los tituli picti delta de las ánforas Dressel 20 entre mediados del siglo I y mediados del siglo III" en: Acta XII Congressus Internationalis Epigraphiae Graecae et Latinae (Barcelona, 3-8 Septembris 2002). Barcelona, 2007, pp. 15-22; AGUILERA, A.; BERNI, P., «Las cifras hispánicas» en: Calligraphia et tipographia. Arithmetica et numerica. Chronologia. Barcelona, 1998, pp. 257-282; OZCÁRIZ, P., «"El Instrumentum domesticum" y el "instrumentum inscriptum" en: ANDREU, F.J. (Coord.), Fundamentos de Epigrafía Latina. Madrid, 2009, pp. 533-577; REMESAL, J. (ed.), Epigrafía anfórica. Barcelona, 2004; id., «Las ánforas Dressel 20 y su sistema epigráfico» en: Epigrafía anfórica. Barcelona, 2004, pp. 127-148. Sobre los últimos hallazgos en el Monte Testaccio: BLÁZQUEZ, J. M.a; REMESAL, J., Estudios sobre el Monte Testaccio (Roma) I. Barcelona 1999; id. Estudios sobre el Monte Testaccio (Roma) II. Barcelona, 2001; id. Estudios sobre el Monte Testaccio (Roma) III. Barcelona, 2003; id. Estudios sobre el Monte Testaccio (Roma) IV. Barcelona, 2007.

${ }_{18}$ Quisiera agradecer a P. Berni su ayuda y asesoramiento en ésta y otras cuestiones relacionadas con la morfología anfórica durante la elaboración de este artículo. 


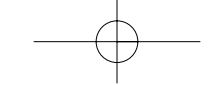

Identificación de dos locales de distribución de vino y aceite en relieves de Isola Sacra

Los dos grupos de ánforas restantes son también relativamente fáciles de identificar, al menos a grandes rasgos. Sus formas se corresponden con ánforas olearias del norte de África. Por la tipología y el tamaño, las de la izquierda representan probablemente el tipo Africana «piccola» ${ }^{19}$ proveniente de la actual Túnez y las de la derecha del tipo Tripolitania $3^{20}$, proveniente de la zona de la actual Libia. Esta opción parece más razonable que identificarlas como ánforas del tipo Africana «grande» ${ }^{21}$, aunque se trata de tipos muy semejantes. En el caso de la Africana «grande», su cronología es más tardía y se trata de un contenedor de conservas de pescado 22 .
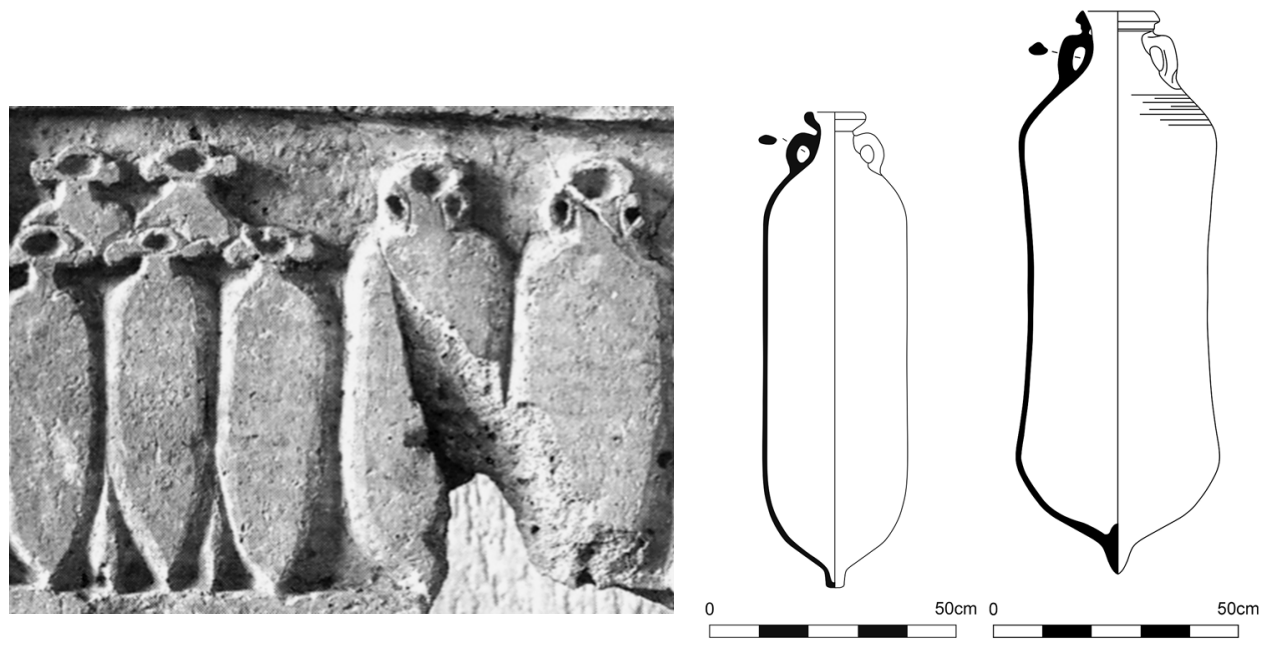

Africana 1 "Piccola" Tripolitania 3

Figs. 7 y 8. A la izquierda, detalle de las ánforas africanas del relieve IPO A 169B. A la derecha, dibujo ánforas Africana 1 Piccolo y Tripolitana 3 provenientes de Ostia (Panella, C., Appunti su un gruppo di anfore della prima, media e tarda etá Imperiale, en: Ostia III. Roma 1973 pp. 460-633).

19 Beltrán 57; Ostia IV; Keay III. Sobre las ánforas Africana 1 y 2, cf. n. 27 y BONIFAY, M., Études sur la céramique romaine tardive d'Afrique. Oxford, 2004; PANELLA, C., «Appunti su un gruppo di anfore deIla prima, media e tarda età Imperiale» en: Ostia III: Le terme del Nuotatore: scavo dell'ambiente $V$ et di un saggio dell'area. Roma, 1973, pp. 460-633; id. «Le anfore africane della prima, media e tarda età imperiale, tipologia e problemi» en: Actes du colloque sur la céramique antique (Carthage, 23-24 juin 1980). Vol. 1. Carthage, 1982, pp. 171-186; PEACOCK, D.P.S.; WILLIAMS, D.F., Amphorae and the Roman economy. An introductory guide. New York, 1986, pp. 153-154.

20 PEÑA (op. cit., p. 23) identificó estas ánforas como Keay 9/11, equivalentes a Tripolitania 2/3. En realidad sólo podría ser el tipo Tripolitania 3, ya que la Tripolitania 2 tiene las asas sobre el cuerpo del ánfora y no sobre cuello. Sobre estas ánforas, cf. PANELLA, C., Appunti su un gruppo..., pp. 460-63; CARANDINI, A.; PANELLA, C., «The trading connections of Rome and Central Italy in the late second and third centuries: the evidence of the terme del Nuotatore excavations, Ostia» en: The Roman west in the Third century. Oxford, 1982, pp. 487-503; PEACOCK, D.P.S.; WILLIAMS, D.F., op. cit., pp. 169-170.

21 Beltrán 56; Ostia III; Keay IV-VII.

22 BONIFAY, M., op. cit. 
En el relieve IPO A 169A se ha conservado un solo ánfora, en el margen superior izquierdo. Su diseño se identifica con el tipo conocido como Gauloise $4^{23}$. Se trata de un contenedor de vino, producido en el sur de Francia, cerca de la desembocadura del Ródano en Languedoc. Podemos descartar que se trate de otro tipo de ánfora como la Dressel $30^{24}$ ya que este tipo anfórico cuenta con un pivote más alargado.
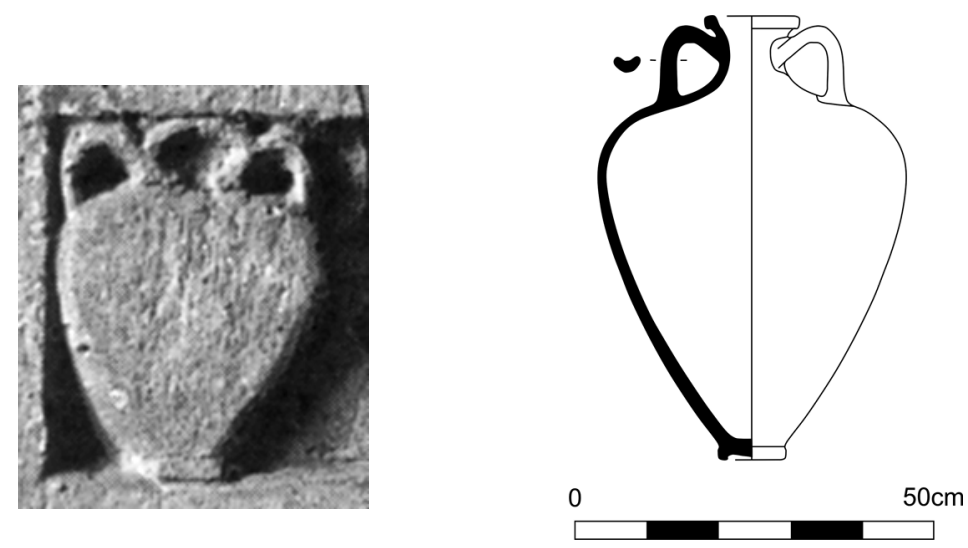

Figs. 9 y 10. A la izquierda, detalle del ánfora del relieve IPO A 169A. A la derecha, dibujo de un ánfora Gauloise 4 provenientes de Ostia (Panella, C., Appunti su un gruppo di anfore della prima, media e tarda etá Imperiale, en: Ostia III. Roma 1973 pp. 460-633).

\section{LAS ÁNFORAS DE LOS RELIEVES, PRESENTES EN OSTIA Y EL MONTE TESTACCIO (ROMA)}

Resulta de gran interés comparar el tipo de ánforas representadas en el relieve con la tipología de ánforas aparecidas en Ostia, con el fin de establecer si la taberna distribuía el aceite habitualmente presente en el lugar de hallazgo. En el edificio de las termas del nadador de Ostia se ha excavado una serie de estratigrafías atribuibles a la fase de construcción y uso de las termas, datables durante la mitad y segunda mitad del siglo II (140-189/190 d.C.), cronología coincidente con la de estos relieves. Se recuperaron 5.000 fragmentos anfóricos, de los cuales aproximadamente una cuarta parte pertenecían a ánforas olearias. El contenedor más

23 Pélichet 47, Ostia LX, Callender 10, Niederbieber 76. LAUBENHEIMER, La production des amphores en Gaule Narbonnaise. Paris 1985; id., «Le vin gaulois de Narbonnaise exporté dans le monde romain» en: LAUBENHEIMER, F., Vingt ans de recherches à Sallèles d'Aude, Languedoc-Rousillon, 2001, pp. 51-65.

24 NACIRI, A., WIDEMANN, F., SABIR, A., «Distinction par activation neutronique des amphores gauloise 4 et de leurs imitations tardives en Maurétanie Césarienne: les Dressel 30", Antiquités Africaines, 22, (1986), pp. 129-140; BONIFAY, M., op. cit.; Panella, C., Appunti su un gruppo di anfore... 
presente es el tipo Dressel 20 de la Bética $(30,9 \%)$, aunque el conjunto de tipos provenientes de la provincia del África proconsular suponen el $58,1 \%$ del total (tipos Ostia LIX y XXIII y Africana I). Los provenientes de la Tripolitania suman un $9,3 \%$ (formas I, II y III) ${ }^{25}$. A partir de finales del siglo II d.C. comienza a fabricarse el tipo Africana II que estará muy presente en Ostia, hasta convertirse en la forma anfórica más habitual.

Por otro lado, las ánforas Gauloise 4 o sus imitaciones están ampliamente atestiguadas en Ostia, siendo uno de los tipos vinarios más comunes hallados hasta ahora ${ }^{26}$. Hay que añadir que las ánforas Gauloise 4 presentes en Ostia a partir de finales del siglo II presentan sistemáticamente las asas alcanzando el borde, tal y como aparecen representadas en el relieve ${ }^{27}$.

Por tanto, las ánforas olearias y vinarias de los relieves de Lucifer formarían parte del conjunto de ánforas olearias y vinarias del contexto de Ostia durante los últimos años del siglo II.

Pero nos llama la atención que los tres tipos de ánforas olearias de Lucifer coincidan exactamente con los tres tipos de ánforas presentes en el Monte Testaccio de Roma durante la segunda mitad del siglo II d.C. ${ }^{28}$. Este yacimiento es una colina artificial de cuarenta metros de alto y más de un kilómetro de perímetro. Está situado dentro de las murallas aurelianas de Roma y fue el antiguo vertedero de las ánforas del aceite importado por la annona a la capital imperial. Está compuesto exclusivamente por unos veinticinco millones de ánforas, de las cuales el $85 \%$ son pertenecientes al tipo Dressel 20 y el $15 \%$ restante a las formas Africana I y Tripolitania $3^{29}$. Lamentablemente, las ánforas no aparecen completas debido a la necesidad de compactación del terreno. Pero, afortunadamente, estas labores de compactación siguieron un sistema organizado, lo que ha permitido contar una cronología precisa de los diferentes estratos. Además, las características del Testaccio han permitido que aquí se hayan conservado las inscripciones pintadas (tituli picti) que en el resto de lugares se han perdido. Por primera vez contamos con una cantidad de infor-

25 PANELLA, C., «I contenitori oleari presenti ad Ostia in eta' antonina: analisi tipologica, epigrafica, quantitativa» en: BLÁZQUEZ, J.M.; REMESAL, J., Producción y comercio del aceite en la antigüedad. Segundo congreso internacional (Sevilla, 24-28 Febrero 1982). Madrid, 1983, pp. 225-262.

26 WIDEMANN, F.; NACIRI, A., «Analisi delle anfore galliche d'Ostia. Variazione delle origini del vino gallico consumato a Roma nelle diverse epoche", en: Amphores romaines et histoire economique. Dix ans de recherche. Actes du colloque de Sienne, 1986. Roma , 1989, pp. 285-296.

27 WIDEMANN, F.; NACIRI, A., op. cit., p. 289.

28 J. THEODORE PEÑA (op. cit., p. 23) ya mencionó, sin profundizar en el tema, que las ánforas del relieve coincidían con las presentes en el Monte Testaccio.

${ }_{29}$ Sobre las ánforas africanas (tipo Africana y Tripolitana) recuperadas en el Monte Testaccio, cf. REVILLA, V., «Las ánforas africanas de las campañas 1989 y 1990 » en: BLÁZQUEZ, J.M.; REMESAL, J., Estudios sobre el Monte Testaccio I. Barcelona, 1999, pp. 75-90; id., «Las ánforas tunecinas y tripolitanas de los siglos II y III d.C.: tipología y circulación» en: BLÁZQUEZ, J.M.; REMESAL, J., Estudios sobre el Monte Testaccio II. Barcelona, 2001, pp. 367-390; id., «Las ánforas africanas del siglo II d.C.», en: BLÁZQUEZ, J.M.; REMESAL, J., Estudios sobre el Monte Testaccio III. Barcelona, 2003, pp. 399-412; id., "Las ánforas tunecinas y tripolitanas de mediados del siglo III d.C. (campañas 1995-1997)» en: BLÁZQUEZ, J.M.; REMESAL, J., Estudios sobre el Monte Testaccio IV. Barcelona, 2007, pp. 317-344 (En esta última publicación aparecen ánforas tipo Africana 2, menos habituales en el Testaccio); MRABET, A.; REMESAL, J. (eds.), In Africa et in Hispania: études sur l'huile africaine. Barcelona, 2007. 
mación abundante y seriada, que convierte al Monte Testaccio en el único archivo económico seriado de la Antigüedad ${ }^{30}$. Las ánforas de aceite presentes en el relieve coinciden, por tanto, con los tres tipos de ánforas que la annona enviaba a la ciudad de Roma durante la segunda mitad del siglo II d.C. ${ }^{31}$.

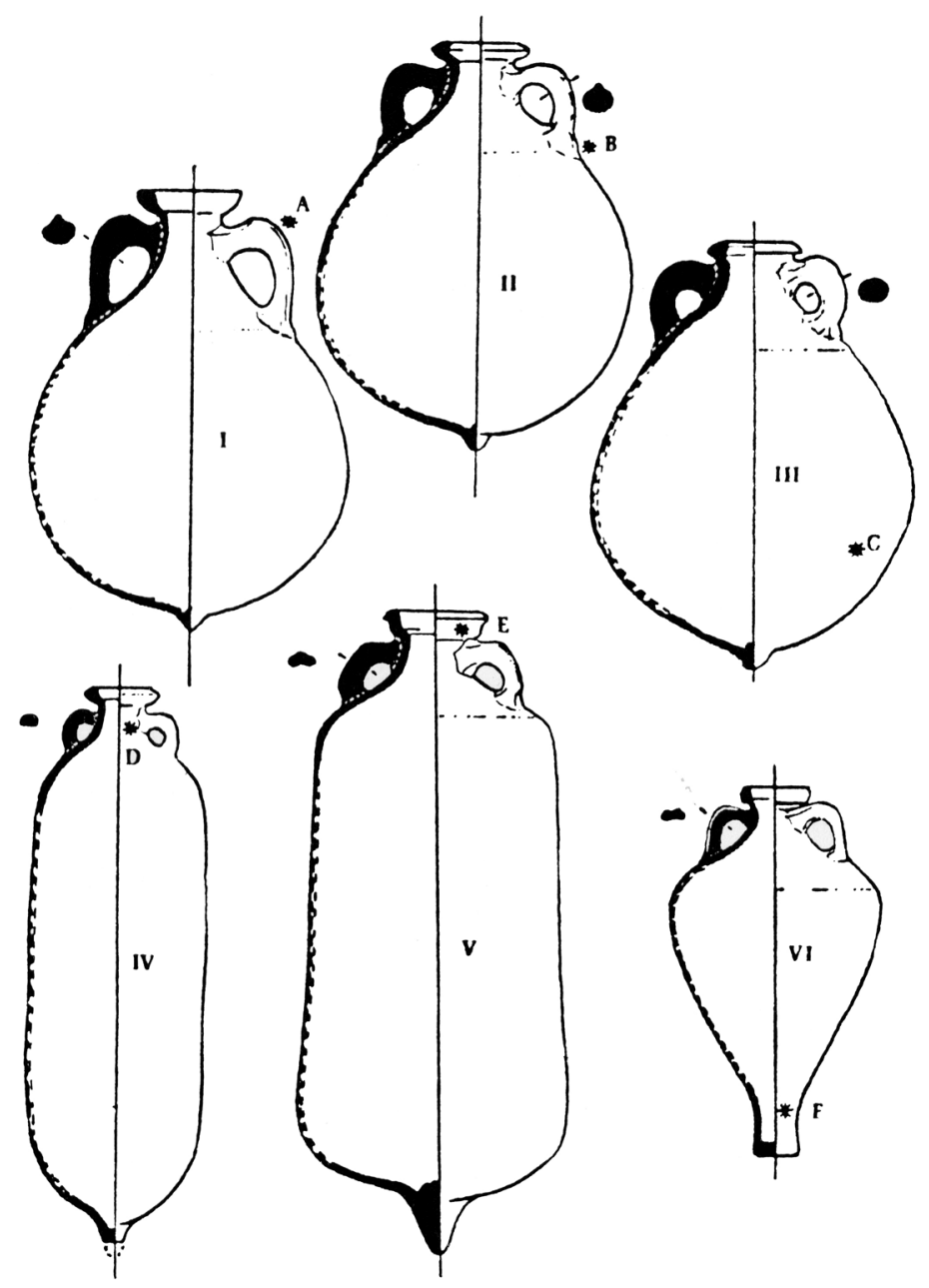

Fig. 11. Cuadro con las principales tipologías anfóricas presentes en el Monte Testaccio, coincidente con las ánforas de los relieves (Rodríguez Almeida, E., Il Monte Testaccio: Ambiente, storia, materiali. Roma, 1984, p. 159). Abajo a la derecha se incluye una Dressel 30, presente en el Testaccio, ya que en el momento de su publicación se creía que contenía aceite.

30 REMESAL, J., Las ánforas Dressel 20..., p. 139.

31 En este momento existen otros tipos anfóricos de carácter residual, cf.: MARIMÓN RIVAS, P; PUIG PALERM, A., «Miscelánea: Las otras ánforas del Monte Testaccio» en: BLÁZQUEZ, J. M. a; REMESAL, J., Estudios sobre el Monte Testaccio (Roma) IV. Barcelona, 2007, pp. 345-379. 


\section{PARALELOS EN EL ARTE ROMANO}

La representación de múltiples tipos de ánforas está ampliamente constatada en el arte romano ${ }^{32}$. En otros relieves podemos encontrar paralelos a los relieves aquí tratados. En la necrópolis de Tor Marancia se recuperó un relieve con una escena de venta de aceite que actualmente se conserva en los Museos Vatica$\operatorname{nos}^{33}$. Se trataría de una taberna de venta de aceite. A la izquierda, bajo un toldo, se encontraría la persona encargada de atender al público, sentado tras un mostrador. A la derecha, catorce ánforas en dos filas. López Monteagudo las ha identificado como ánforas olearias africanas, probablemente semejantes a las del tipo Africano del relieve IPO A $169 \mathrm{~B}^{34}$.

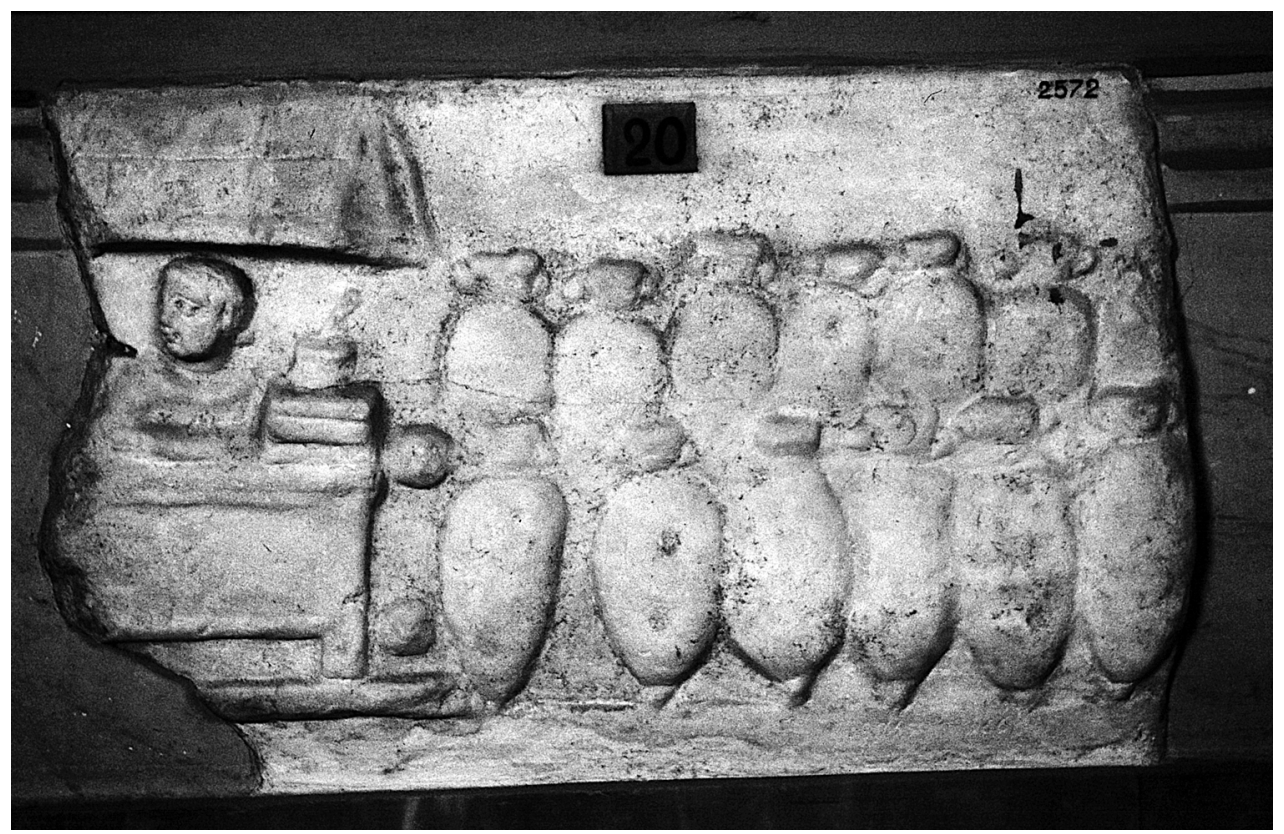

Fig. 12. Imagen de relieve de una taberna de venta de aceita procedente de la necrópolis de Tor Marancia. Fuente: López Monteagudo, G., El aceite en el arte antiguo, en:

Blázquez, J.M.; Remesal, J., Estudios sobre el Monte Testaccio (Roma) IV. Barcelona 2007 p. 512.

${ }^{32}$ Sobre las ánforas de aceite, cf. los excelentes trabajos de LÓPEZ MONTEAGUDO, G., «Producción y comercio de aceite en los mosaicos romanos» en: L'Africa romana XII. Sassari, 1998, pp. 359-376; id., “¿Ánforas hispánicas en un mosaico de Herculano?», AnMurcia, 17-18, (2001-2002), pp. 375-382; id., «El aceite en el arte antiguo», en: BLÁZQUEZ, J.M.; REMESAL, J., Estudios sobre el Monte Testaccio (Roma) IV. Barcelona, 2007, pp. 433-520; BLÁZQUEZ, J.M.; GARCÍA-GELABERT, M.P.; LÓPEZ MONTEAGUDO, G., «El transporte marítimo de ánforas en los mosaicos romanas», en: Alimenta. Estudios en homenaje al Dr. Michel Ponsich. Madrid, 1991, pp. 323-328; SAN NICOLÁS PEDRAZ, M.P., «El transporte marítimo en los mosaicos romanos», en: L'Africa romana XIV. Sassari, 2002, pp. 241-266.

${ }_{33}$ LIPPOLD, G., Die Skulpturen des Vatikanischen Museums III/2. Berlin, 1956, p. 247; 546-547; t. 113.

${ }^{34}$ LÓPEZ MONTEAGUDO, G., El aceite en el arte antiguo..., p. 512. 
En Cherchel (Argelia) se conserva la siguiente inscripción funeraria de $P$. Livius Phileros, un liberto de la zona: $P($ ublio)(?) Livio(!) $P($ ubli)(?) Eu/sexti(!) libertus $/ P(h)$ ileros oliarius(!) / $h$ (ic) s(itus) e(st) annorum / XXXXIIX cip(p)um / fecit Valeria viro / suo pro meritis ${ }^{35}$. Va acompañada de una escena en la que se representa el difunto que, como él mismo indica, tenía la profesión de olearius. López Monteagudo lo describe de la siguiente forma: «debajo del epitafio se ha esculpido un relieve que figura un personaje masculino en pie en posición frontal, vestido con una amplia túnica hasta los pies, de manga corta, dispuesto a verter, mediante un embudo que sujeta con la mano izquierda, en una vasija de cuello estrecho el aceite contenido en un gran recipiente esférico, situado sobre el suelo a su derecha, y que él recoge con el cucharón que lleva en la mano derecha»36. Creemos que resulta interesante comparar esta acción con la del personaje que atiende el local de venta de aceite de Lucifer (figuras 13 y 14).
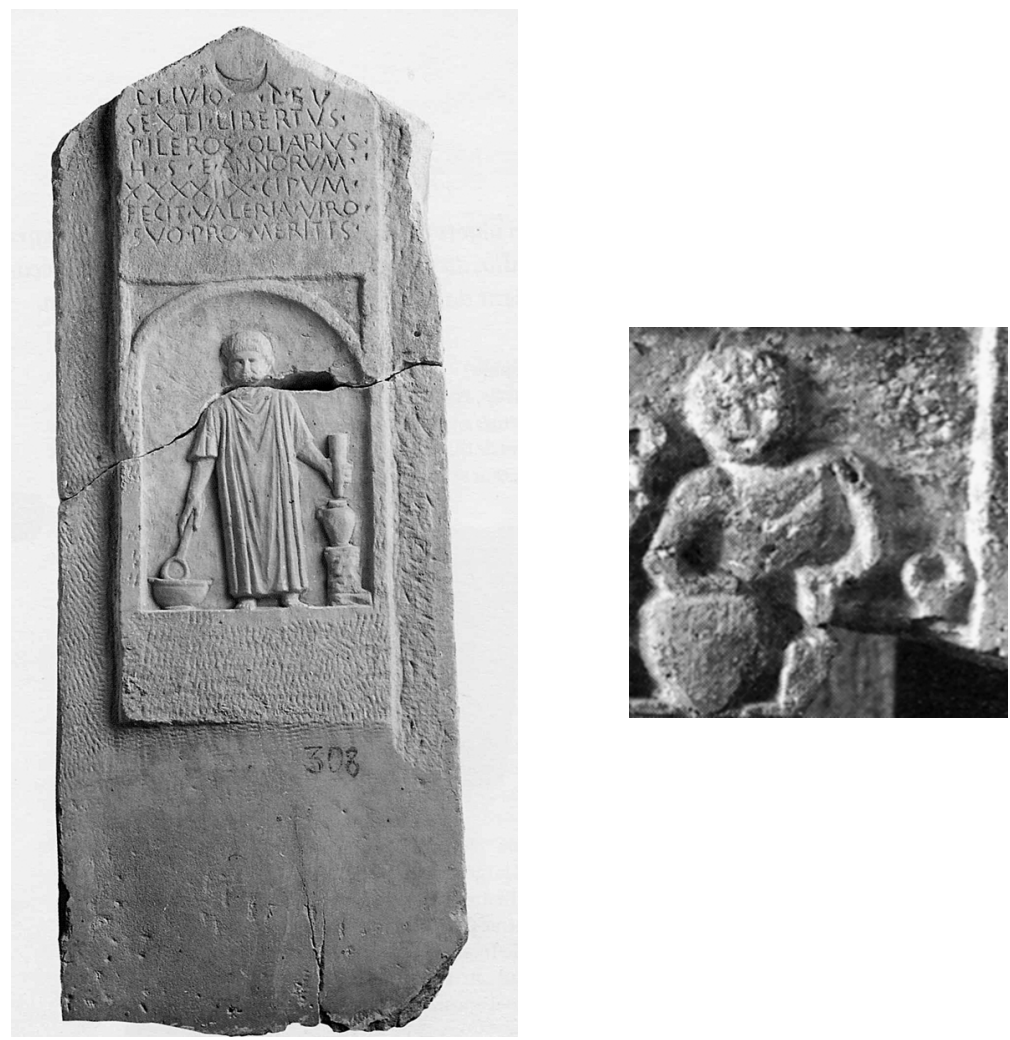

Figs. 13 y 14. A la izquierda, relieve funerario de un olearius procedente de Cherchel. A la derecha, detalle del proceso de trasvase de aceite en el relieve de Isola Sacra. Fuente figura 13: López Monteagudo, G., El aceite en el arte antiguo, en: Blázquez, J.M.; Remesal, J., Estudios sobre el Monte Testaccio (Roma) IV. Barcelona 2007 p. 512.

${ }^{35} A E$ 1925, 45b=HD025678.

36 AA.VV., Algérie antique. Arles 2003 p. 137, n. ${ }^{\circ} 57$. 


\section{ANÁLISIS DE DOS LUGARES DE DISTRIBUCIÓN OLEARIA Y VINARIA}

Después de lo expuesto anteriormente creemos que no existe lugar a dudas de que el relieve IPO A 169B representa un lugar de venta de aceite ${ }^{39}$. La escena parece dibujar un pequeño establecimiento de dos pisos y nueve ánforas, con aceites provenientes de la Bética y el norte de África. El relieve IPO A169A, por el contrario, presentaría un ánfora de vino y un gran contenedor que podría ser de otro líquido. La cronología de las formas anfóricas remiten a finales del siglo II-principios del siglo III. El tipo de establecimiento coincide con las tabernae conservadas en Portus u Ostia ${ }^{40}$. La taberna localizada al lado de la casa de Neptuno y Anfitrite en Herculano tiene grandes semejanzas. En ambas existe un segundo piso en el que se encuentran almacenadas diversas ánforas de vino, y cuenta con un dolium exento como el del relieve ${ }^{41}$.

No creemos que la escena esconda algún tipo de esquematismo que disminuya la verdadera entidad del establecimiento. Se trataría, por tanto, de una taberna de distribución de aceite. Su dueño, el difunto que encargó el relieve, formaría parte de una "clase media» acomodada a la que nos hemos referido anteriormente. No debemos olvidar que la necrópolis de Isola Sacra destaca por la homogeneidad social de sus ocupantes ${ }^{42}$ y que este relieve forma parte de un conjunto homogéneo en tipología y contenido.

Quisiéramos poder precisar más en torno a los recipientes situados en la zona inferior de las tabernae. A pesar de los fragmentos que faltan podemos intuir que en ambas escenas tiene especial relevancia al proceso de cálculo de cantidades líquidas. La ley obligaba a que en todo establecimiento público existiese un juego de pesos y medidas calibradas según un patrón estandarizado ${ }^{43}$. Los reci-

39 Debido al contenido exclusivo de aceite de las ánforas identificadas, y porque en ningún caso se puede interpretar que en la inscripción se repita el término Aquatarius presente en IPO A 169A (como parece deducirse de CALZA en: La necropoli del 'Portus Romae..., p. 540), no hay razón alguna para pensar que en dicha taberna se comerciase también con agua, como sugiere J. T. PEÑA (op. cit., p. 23).

${ }_{40}$ GIRRI, G., La taberna nel quadro urbanistico e sociale di Ostia, Roma, 1956; GRIMALDI BERNARDI, G., op. cit. Cf. especialmente pp. 18-31.

41 GRIMALDI BERNARDI, G., op. cit., pp. 28-30.

42 BALDASSARRE llega a ser categórica, hasta el punto de afirmar que «si tratta di una omogenea classe media in evoluzione, senza che nessuno dei suoi componenti appartenga ad uno strato più distinto della società» (La necropoli dell'lsola Sacra... (2002), p. 20). También señala que, fuera de este tipo de tumbas monumentales a las que pertenece el relieve que nos ocupa, existen hasta seiscientas sepulturas realizadas con medios mucho más humildes, que pertenecerían a un grupo social inferior y muy diferenciado del primero.

${ }^{43}$ Lex Silia de ponderibus publicis. Fest. f. 244: Ex ponderibus publicis quibus hac tempestate populus oetier solet, uti coaequetur; se dolo malo, uti quadrantal uini $L X X X$ pondo siet; congius uini $X p$ (ondo) siet $\ldots=$ =Para las medidas públicas de las que el pueblo tiene costumbre de servirse en estos tiempos, se las regle sin fraude; que el quadrantal sea igual a un peso de vino de 80 libras, el congio a un peso de vino de 10 libras...» (trad.: AGUILERA MARTíN, A.; GARCÉS ESTALLO, I., «La inscripción ante cocturam de Esplujals (Foradada, La Noguera, Lleida). Un congiario para mulsum», Pyrenae, 28, (1997), p. 276).; Dig. 33, 7, 13: Tabernae cauponiae instrumento legato, etiam institores contineri, Neratius existimat. Sed videndum, ne inter instrumentum tabernae cauponiae, et instrumentum cauponae set discrimen: ut tabernae non nisi loci instrumenta sint, ut dolia, vasa, ancones, calices, trullae, quae circa coenam solent traiici; item urnae areae, et congiaria, sextaria, et similia ... = «En el legado de las pertenencias de una taberna o una tienda cree Neratius que entran también los esclavos que están al frente del negocio. Pero cabe pregun- 
pientes de la zona del mostrador son muy semejantes a los presentes en la pintura de Pompeya mencionada anteriormente (Fig. 16) ${ }^{44}$. La composición de esta escena nos hace pensar que se trata de capacidades regladas. En el nivel inferior de las tabernas de Lucifer aparecen tres tipos de contenedores menores. Las jarras más pequeñas situadas en una franja por encima del dependiente, o el pequeño contenedor con el que éste traslada el aceite podrían equivaler a una hemina $(0,274$ litros). El recipiente del personaje que se encuentra junto al gran recipiente IPO A 169A podría corresponder a un sextarius (0,54 litros), que por otro lado era la medida estándar a la hora de vender el vino ${ }^{45}$. Los dos recipientes más grandes situados sobre el mostrador de IPO A 169B, podrían tener una capacidad cercana a los 3,28 litros que contenía un congium. Ciertamente, en este caso el congium no sería semejante al congio Farnese ${ }^{46}$, ni tampoco cuenta con el tipo de asa del congiario recuperado en Foradada (La Noguera) ${ }^{47}$. Hemos observado que se trata del mismo recipiente que el que se encuentra encima del mostrador de una taberna representada en otro relieve de Isola Sacra, con la misma capacidad aproximada ${ }^{48}$. No es posible identificar con claridad el instrumento con el que se encuentra traspasando el aceite desde un recipiente al otro, pero aquél debería coincidir con alguna de las medidas mencionadas anteriormente. El dolium de la taberna IPO A $169 \mathrm{~A}$ no creemos posible adscribirlo a ninguna de las medidas estándar, ya que resulta demasiado grande para contener un ánfora (26,26 litros), pero demasiado pequeño como para contener un culleus (525,20 litros).

Debemos hacer una reflexión sobre el término aquatarius. Esta palabra no aparece en ninguna fuente clásica literaria ni epigráfica, ni en ningún diccionario de latín clásico. La mayoría de autores citados en este artículo la interpretan como «aguador» o vendedor de agua. Parece claro que se trata de un término creado a partir de una profesión relacionada con el agua, añadiendo la terminación -ius. En este caso se trata de un cognomen cuyo significado hace referencia a una profesión. Sólo suelen ser coincidente el cognomen con la labor profesional del personaje cuando éste no ha recibido el cognomen al nacer, y se le incorpora más adelante, cuando ya tiene una profesión ${ }^{49}$. Gummerus señala que esto se aplicaba de forma más habitual en fechas muy anteriores al último tercio del siglo II d.C. Por otro lado, Kajanto estableció la teoría según la cual, cuanto menor es la frecuencia de un cognomen relativo a una profesión, mayor es la posibilidad de que se trate de una verdadera referencia a su labor ${ }^{50}$. En nuestro caso el cognomen es único, lo

tarse si no hay diferencia entre las pertenencias del local de un hostal y las del hostal, de suerte que las del local no sean más que las pertenencias de la instalación, como las dolia, vasijas, jarros, copas y jarras que suelen hacerse circular en la comida, así como las urnas de bronce, congios, sextarios y similares...» (trad.: AGUILERA MARTÍN, A.; GARCÉS ESTALLO, I., op. cit., p. 276).

44 GRIMALDI BERNARDI, G., op. cit., p. 70.

${ }^{4}$ Es precisamente esta cantidad la que ha consumido el viajero de la famosa inscripción de Aesernia (CIL IX 2689); HERMANSEN, G., Ostia: Aspects of Roman City Life. Alberta, 1981, p. 191..

46 POTTIER, E., «Congius (s.v.)», en: Dictionaire des Antiquités grecques et romaines, 2, pp. 1444-1445.

47 AGUILERA MARTÍN, A.; GARCÉS ESTALLO, I., op. cit..

48 CALZA, G., La necropoli del 'Portus Romae..., pp. 531-532; HERMANSEN, G., op. cit., p. 187.

49 GUMMERUS, H., «Cognomen und Beruf» en: Commentationes in honorem Ivar August Heikel. Helsinki, 1926, pp. 48-74.

50 KAJANTO, I., The Latin Cognomina. Helsinki-Helsingfors, 1965, p. 83. 
cual nos permitiría suponer que Aquatarius o su padre habrían ejercido algún tipo de profesión relacionada con el agua. Estamos de acuerdo con Solin en que se trata de un cognomen, el de su patrono o el de su padre ${ }^{51}$. En este caso podríamos afirmar que, con gran probabilidad, su padre o su patrono habría sido aguador, pero Lucifer probablemente no. De este modo, creemos que el desarrollo de la inscripción de IPO A 169A debería ser: Lucifer Aquatari (servus) o las variantes (Iibertus) o (filius).

Si todavía quedase alguna duda acerca de la hipotética venta de agua en el lugar, tenemos que señalar que de todos los elementos mostrados en las dos escenas que estamos glosando, sólo el gran recipiente situado a la derecha de IPO A 169A sería susceptible de contener de agua. Realmente podría contenerla, ya que el agua era un elemento imprescindible en todas las tabernas de Ostia, hasta el punto de que las conducciones directas mediante fistulae se repiten en muchas de ellas ${ }^{52}$. Pero carecemos de cualquier argumento para defender que se trate de agua y no de otros líquidos o productos presentes en los dolia de las tabernae, como grano o legumbres.

Por otro lado, d'Ambra, escribiendo sobre el relieve de Scribonia Attice señala que este tipo de relieves de Isola Sacra están realizados con una función primordialmente descriptiva ${ }^{53}$, que en este caso haría redundante la inscripción. Si aquatarius fuese el nombre de la profesión del difunto, también podría producir una paradoja ya que el texto señalaría que se dedica a la venta de agua mientras que el ánfora de la taberna indica claramente que vende vino ${ }^{54}$. Las ánforas que se presentan en estos dos relieves eran claramente identificables para cualquier viandante, como lo son hoy en día las botellas de algunos refrescos o las de algunos productos de limpieza. Por tanto, cualquier caminante sabría qué se vendía en el establecimiento sin necesidad de leer la inscripción.

Queda por establecer la relación que existió entre los relieves IPO A 169A e IPO A 169B. Creemos que no cabe duda que forman parte de un mismo conjunto, por las semejanzas a las que hemos hecho referencia anteriormente. Es más, creemos que se trata del mismo modelo de taberna: hasta ahora no se ha destacado que en la zona situada encima del mostrador y del dependiente de IPO A 169A se ha diseñado el mismo espacio elevado que en IPO A 169B era ocupado por la inscripción. Pero en este caso, sin ningún epígrafe. Es decir, que se trata del mismo diseño de taberna. Pero también existen algunas diferencias importantes. Principalmente dos: la venta de dos productos diferentes (vino y aceite) y la presencia de cognomina diferentes en cada uno. Que ambos relieves hagan alusión a la venta de dos productos diferentes nos remite a una familia que tenía tabernae de venta de vino y aceite, y quería representarlo mediante dos relieves paralelos el uno del otro. En otras tumbas como la número 100 de Scribonia Attice se han conservado in situ dos relieves colocados de forma simétrica mostrando dos actividades profesionales

51 SOLIN H., op. cit., p. 123.

52 HERMANSEN, G., op. cit., pp. 187-190.

53 HERMANSEN, G., op. cit., p. 78-80.

54 Sólo estaría justificado si se dedicase a vender agua destinada a la mezcla con el vino. 
semejantes, pero diversas: la escena de una actividad de una matrona ejerciendo en un parto y la de un cirujano con parte de su instrumental ${ }^{55}$. Parece claro que se trataría de dos profesiones diferentes de los miembros de la familia a la que pertenecía la tumba, y podríamos trazar un cierto paralelismo con los relieves de Lucifer. En nuestra opinión se trata de dos personajes llamados Lucifer (muy probablemente libertos) de una misma familia que contaba con tabernae dedicadas a la venta de aceite y vino. Si ambos relieves fuesen del mismo personaje, esperaríamos que en los dos apareciese la misma filiación o referencia a Aquatarius.

También cabría preguntarse si el lugar representado se trataría de una simple taberna de venta de aceite o de un local diferente, quizás una mensa olearia ${ }^{56}$. Esta opción resultaría sugerente, pero éstas se encontraban en la Urbs y no tenemos conocimiento de que pudiesen existir en otros lugares ${ }^{57}$. La lectura de la inscripción realizada por Thylander, LUCI[FER] ONOVS / N $O^{58}$, nos hizo pensar en la siguiente reconstrucción: Luci[fer----]ondvs / N(egotiator) O(learivs). Se trataría hipotéticamente de un negotiator, figura ya atestiguada en numerosos epígrafes ${ }^{59}$. Pero la nueva lectura de Pentti-Tuomisto (Luci[fer ? p]ondus /n[-1-2-]+das ${ }^{60}$ ) parece desterrar esta posibilidad ${ }^{61}$. Como segunda hipótesis alternativa (aunque remota) a la de la taberna, no podemos descartar totalmente la opción de que IPO A 169B represente algún tipo de establecimiento u horreum en el que los mensores de la annona controlaban el aceite llegado a Ostia con destino a Roma. La annona reconocía en Ostia la llegada de todo el aceite que importaba, y contaba con numerosos horrea. Conocemos difusores olearii provenientes de la Bética que están estrechamente relacionados con Ostia. Aquí se han encontrado, por ejemplo, sellos en ladrillo del difusor olearius M. Cassius Sempronianus, originario de Olisipo ${ }^{62}$. Quizás podría tratarse de algún tipo de personal administrativo subordinado al procurator annonae de Ostia, o a cualquiera de las numerosas oficinas o tabularii existentes en el lugar63. La palabra pjondus situada en la inscripción podría hacer referencia a la labor de pesaje ${ }^{64}$ aunque, como hemos señalado anteriormente, no está claro el contexto de esta palabra dentro de la inscripción. La coincidencia de

55 SQUARCIAPINO, M.F., op. cit., pp. 183-184; D'AMBRA, E., op. cit., p. 74-75.

56 CAGNAT, R., «Mensor (s.v.)», en: Dictionaire des Antiquités grecques et romaines III 2. Paris, 1926, pp. 1726-1727.

57 PAVIS D'ESCURAC, H., La préfecture de l'annone service administratif impérial d'Auguste à Constantin. Rome, 1976, pp. 11ss.

58 THYLANDER, H., IPO A 169b (PI. XLIX: 2).

59 GARCÍA, G., Mercatores y negotiatores: ¿simples comerciantes?, Pyrenae, 30, (1999), pp. 173190.

60 PENTTI-TUOMISTO, M., 306..., pp. 311-312.

61 Mientras que los trazos de la parte izquierda de la inscripción son firmes y profundos, los de la derecha parecen débiles y poco profundos, hasta el punto que la fotografía aportada por Pentti-Tuomisto ofrece muchas dudas acerca de la voluntariedad de los trazos AS de la segunda fila.

62 REMESAL RODRÍGUEZ, J., «Promoción social en el Imperio romano a través del comercio» en: MARCO SIMÓN, F.; PINA POLO, F.; REMESAL RODRÍGUEZ, J., Vivir en tierra extraña: emigración e integración cultural en el mundo antiguo. Barcelona, 2004, pp. 125-136; BERNI MILLET, P. Epigrafía anfórica de la Bética. Nuevas formas de análisis. Barcelona, 2008, p. 391, n. 41.

63 PAVIS D'ESCURAC, H., op. cit., pp. 122 ss.

${ }^{64}$ MICHON, E., «Pondus (s.v.)» en Dictionaire des Antiquités grecques et romaines IV 1. Paris, 1926, pp. 552-563. 
los tres tipos de ánforas que el difunto muestra almacenadas en el local con la tríada de ánforas presente en el Testaccio durante la segunda mitad del siglo II d.C. apoyaría esta hipótesis.

En definitiva, creemos que queda desterrada la posibilidad de que estos locales fuesen tabernae de venta de agua, mientras que la opción de que representen dos tabernae de venta de vino y aceite al por menor de finales del siglo II o principios del III nos parece la opción más verosímil, hasta el momento en el que se consiga reconstruir la inscripción IPO A 169B o se localicen los fragmentos perdidos de ambos relieves. 